\title{
The Effectiveness of Acupressure Therapy and Aromatherapy of Lemon on the Ability of Coping and Emesis Gravidarum in Trimester I Pregnant Women at Langsa City Community Health Centre, Aceh, Indonesia
}

\author{
Magfirah Magfirah $^{1 *}$, S. Fatma ${ }^{2}$, Idwar Idwar ${ }^{2}$ \\ ${ }^{1}$ Department of Midwifery, Ministry of Health Polytechnic of Langsa, Aceh, Indonesia; ${ }^{2}$ Department of Nursing, Ministry of \\ Health Polytechnic of Langsa, Aceh, Indonesia
}

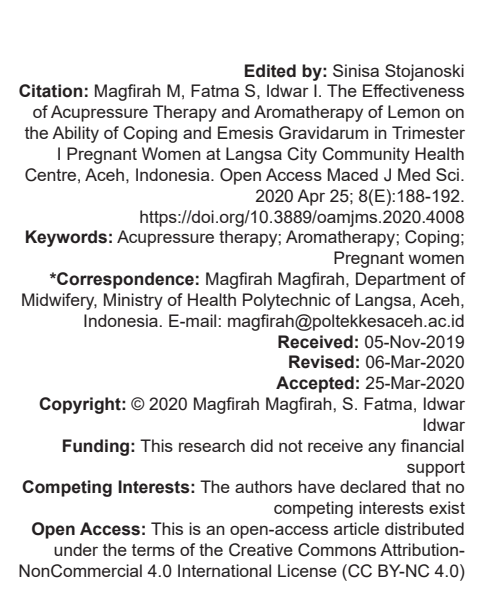

\section{Introduction}

During the pregnancy period, various changes occur both physical and psychological changes that allow the cause of problems in pregnancy, especially the first-trimester pregnancy. One of the problems that arise is nausea and vomiting which is commonly called morning sickness which normally occurs. Nausea and vomiting of pregnancy (NVP) are among the most common complaints of women during pregnancy that $50-80 \%$ of women have experienced various degrees of it [1]. NVP is a normal, commonly experienced affliction of early pregnancy. Despite this, its impact on women's lives is not necessarily minimal. For some women, the implications of NVP are substantial with multifaceted effects, hindering their ability to maintain normal life activities, and particularly their ability to work [2], [3]. Nowadays, the tendency in women to use non-medicinal and herbal products in pregnancy has increased due to concerns about adverse drug effects in early pregnancy [4]. One alternative to overcome nausea and vomiting in pregnancy is nonpharmacological is to use aromatherapy.

Aromatherapy is an alternative treatment that has been recognized by the $\mathrm{WHO}$; treatment with aromatherapy eliminates pain, improves mood, increases relaxation, and reduces anxiety and stress [5], [6]. Aromatherapy is commonly used and has been practiced for centuries; few high-quality empirical reviews have examined its effectiveness in reducing pain [7]. In general, aromatherapy can be used to treat various episodes of illness, digestive disorders, headaches, insomnia, muscle 
aches, reshuffle problems, skin diseases, swollen joints, urine-related complications, and others [8]. Aromatherapy is the most commonly applied topically, or through inhalation. Several types of essential oils can be used as aromatherapy, including peppermint, spearmint, lemon, and ginger. Lemon aromatherapy is an essential oil produced from orange peel extract (Citrus lemon) which is often used in aromatherapy. Lemon aromatherapy is a type of aromatherapy that is thought to be safe for treating pain during pregnancy and childbirth. Lemon essential oil (Citrus lemon) is one of the most widely used herbal oils in pregnancy and is considered a safe drug in pregnancy. Lemon contains Limonene which will inhibit the action of prostaglandins so as to reduce pain and function to control cyclooxygenase I and II, prevent prostaglandin activity, and reduce pain, including nausea and vomiting [9]. The lemon scent is an effective way to control the symptoms of nausea and vomiting [10]. Lemon contains Limonene which will inhibit the action of prostaglandins so that it can reduce pain and function to control cyclooxygenase I and II, prevent prostaglandin activity, and reduce pain, including nausea and vomiting [11]. Essential oils are widely used in aromatherapy in mild mood disorders and to minimize anxiety symptoms caused by stress. The purpose of this study was to analyze the effects of acupressure therapy and the aroma of lemon therapy on the ability to cope and emesis gravidarum in trimester I pregnant women at the city health center Langsa, Aceh province, Indonesia.

\section{Methods}

This research used a quasi-experiment. The design used was a non-randomized pretest-posttest control group design. The intervention group was given acupressure and aromatherapy treatment, while the control group was given a standard intervention. This research was conducted in the West Langsa Health Center in Langsa City from January 2019 to March 2019. The population was all first-trimester pregnant women with complaints of nausea and vomiting in the Langsa City Health Center. The number of samples was 60 respondents. Each group consisted of 20 respondents. Respondents were divided into three groups. The first group was acupressure, the second group was acupressure + lemon aromatherapy and the third group was control. Data analysis using univariate analysis, bivariable analysis using paired t-test, dependent t-test, and one-way ANOVA, multi-variable analysis using a multi-covariance test (multivariate analysis of covariance/ANOVA).

\section{Results}

\section{Univariate analysis}

The univariate analysis aimed at describing the characteristics of research subjects which include groups, education level, occupation, age, gestational age, and Gravida is presented in Table 1.

Table 1: Characteristics of respondents

\begin{tabular}{lll}
\hline Variable & $\mathrm{n}$ & $\%$ \\
\cline { 3 - 3 } & & Mean \pm SD (Min-Max) \\
\hline Group & 20 & 33.3 \\
$\quad$ Acupressure & 20 & 33.3 \\
$\quad$ Acupressure and lemon & 20 & 33.3 \\
$\quad$ Control & & \\
Educational level & 8 & 13.3 \\
$\quad$ Bachelor & 1 & 1.6 \\
$\quad$ Diploma II & 2 & 3.3 \\
Diploma III & 28 & 46.7 \\
$\quad$ High school & 9 & 15.0 \\
$\quad$ Junior school & 12 & 20.0 \\
$\quad$ Primary school & & \\
Occupation & 54 & 90.0 \\
$\quad$ Housewife & 6 & 10.0 \\
$\quad$ Civil servants & 60 & $28.4 \pm 8.2(15-42)$ \\
Age & 60 & $7.8 \pm 2.1(4-11)$ \\
Pregnant age & 60 & $2.8 \pm 1.9(1-7)$ \\
Gravida & & \\
\hline
\end{tabular}

The univariate analysis is divided into three groups: two treatment groups and one controlled group. The education level of the respondents was dominated by high school, $46.7 \%$ (28 people). Respondents' occupations were mostly housewives, 90.0\% (54 people). The average age of respondents was 28.4 years, the lowest was 15 years and the highest was 42 years. The gestational age being experienced is an average of 7.4 weeks, the lowest 4 weeks and the highest gestational age of 11 weeks. Furthermore, a normality test is performed to determine whether the data to be tested is normally distributed or not.

In Table 2, the results show that the pre-test data for emesis gravidarum consisting of nausea and vomiting obtained data distribution normally distributed with $p>0.05$. Conversely, the maternal coping ability of the pre-test data values was not normally distributed with a $p<0.05$. Pre-test scores on family support data are normally distributed while the age of data distribution is not normally distributed.

Table 2: Normality test using sekuen test

\begin{tabular}{llll}
\hline Variable & $\mathrm{Z}$ & $\mathrm{p}$ value & Information \\
\hline Pre-nausea test & 1.5 & 0.06 & Data is normally distributed \\
Pre-vomiting test & 0.1 & 0.45 & Data is normally distributed \\
Pre-coping test & 1.9 & 0.02 & Data not normally distributed \\
Pre-family support tests & -0.6 & 0.74 & Data is normally distributed \\
Age & 3.7 & 0.00 & Data not normally distributed \\
\hline
\end{tabular}

\section{Bivariate analysis}

This analysis aims to look at the effect of independent variables, namely, the administration of acupressure therapy, acupressure + lemon aromatherapy, and control of the decrease in emesis gravidarum and increased coping. 
The analysis results above show that the acupressure and acupressure + lemon aromatherapy groups decreased the amount of nausea with a decrease of 4.2 and 4.85 , respectively. This decrease is very significant with a $p=0.0001$. Whereas the controlled group did not decrease, but there was an increase in the nausea of 0.2 . These results mean that acupressure and acupressure + lemon therapy are effective in reducing nausea experienced by pregnant women. Respondents who received acupressure therapy and acupressure + aromatherapy lemon experienced a decrease in vomiting of 1.55 and 4.3, respectively. Acupressure and acupressure + lemon are effective in reducing the duration of vomiting in pregnant women. Whereas in the controlled group, there was no decrease in the duration of vomiting in pregnant women, instead, there was an increase in the duration of vomiting by 0.15 . Paired t-test results for coping abilities, the results obtained that acupressure therapy, acupressure + aromatherapy lemons, and controls all increased the average value of coping abilities.

The biggest increase in coping ability in pregnant women lies in the treatment of lemon acupressure + aromatherapy, which is 6.2. The increase in both treatments was significant with a $p=0.0001$, respectively. While the increase for the control group was only 0.5 and it was not significant. These results indicate that acupressure and acupressure + lemon therapy are effective for increasing the coping abilities of pregnant women.

ANOVA analysis results showed that there were significant differences in nausea between treatment groups with a $p=0.0001$. Bonferroni test results revealed that there was a difference between the acupressure group and the control group that was large (4.4) and this difference was significant. This means that pregnant women treated with acupressure complained of nausea by 4.4 when compared to the control group. In the acupressure + aromatherapy lemon group with a control group, there was a difference $(-5.5)$. Lemon acupressure + aromatherapy therapy reduced the average of nausea by 5.5 compared to the control group and this reduction was significant. The acupressure group against lemon acupressure + aromatherapy had a difference of a decrease of 0.65 and this decrease was not significant.

ANOVA analysis results show that there were significant differences in vomiting between treatment groups with a $p=0.0001$. The greatest decrease in average vomiting occurred in the acupressure + aromatherapy lemon group (4.30), the acupressure group (1.55), and then the control group (0.15). Bonferroni test results found that there was a difference of $(-1.7)$ in the acupressure group compared with the control group. The difference means that acupressure therapy will reduce vomiting by an average of 1.7 compared to the control group. The difference between the acupressure + lemon group against the control group was -4.45 with a $p=0.0001$.
The acupressure + lemon group reduced the vomiting of pregnant women by 4.45 compared to the control group. The difference between acupressure + lemon aromatherapy and acupressure is $-2.75 p=0.0001$. The lemon acupressure + aromatherapy group reduced vomiting in pregnant women by 2.75 compared to the acupressure group. The results of this study indicate that the lemon acupressure + aromatherapy group was most effective at reducing vomiting in pregnant women when compared to the other two groups.

The highest increase in coping skills was found in the lemon acupressure + aromatherapy treatment group (6.20), the acupressure group (3.20), and the control group (0.50). The difference between the acupressure group and the control group was 2.7. This result means that the acupressure group increased the coping ability of pregnant women by 2.7 compared to the control group. The difference between the acupressure and acupressure + lemon aromatherapy groups with control was significant $(p<0.0001)$. The lemon acupressure + aromatherapy group increased the coping ability of pregnant women by 5.7 compared to the control group. The difference between acupressure + lemon aromatherapy and acupressure is 3 with a $p$ $=0.04$. This value indicates that the acupressure + lemon aromatherapy group differed significantly in increasing the coping ability of pregnant women when compared to the acupressure group. The most effective group for improving the coping ability of pregnant women is the lemon acupressure + aromatherapy group.

The correlation between age to nausea, vomiting, and coping, in general, showed insignificant results with a value of $p>0.05$. The negative correlation on age lies in nausea which means that the higher the age of pregnant women, average nausea decreases by 0.09 , whereas the variable vomiting and coping abilities occur positive correlation. In the correlation of variable support for nausea and vomiting, there were negative correlations of -0.41 and -0.58 , respectively, with a significance value of 0.001 . While the correlation between supports for coping skills is positive with a coefficient value of 0.45 and a significance value of 0.003 , this result can be interpreted that family support will reduce nausea and vomiting, respectively, by 0.41 and 0.58. Family support will increase the coping abilities of pregnant women by (0.45.).

The acupressure and acupressure + lemon aromatherapy groups decrease the incidence of nausea in pregnant women significantly after being controlled by a support family (Table 3 ). The reduction in nausea in the lemon acupressure + aromatherapy group was higher when compared to the acupressure group. $\mathrm{R}^{2}$ value obtained at a nausea variable of 0.55 . This value means that the treatment group and support contribute to a reduction in nausea in pregnant women by $55 \%$. The thing the opposite occurs in family support variables that increase nausea by 0.04 and this increase is not significant. The value of R2 obtained 
on the variable vomited 0.77 . Treatment groups and family support for pregnant women contribute to a reduction in vomiting of $77 \%$. In the variable gag group, acupressure and acupressure + lemon aromatherapy have been shown to reduce the rate of vomiting significantly after being controlled with support variables. Table 3: Paired t-test results between the acupressure, acupressure + lemon aromatherapy groups, and control of nausea, vomiting, and coping

\begin{tabular}{|c|c|c|c|c|c|}
\hline Variable & $\begin{array}{l}\text { Pre-test } \\
\text { Mean } \pm S D\end{array}$ & $\begin{array}{l}\text { Post-test } \\
\text { Mean } \pm \text { SD }\end{array}$ & Different & T-count & $p$ value \\
\hline \multicolumn{6}{|l|}{ Nausea } \\
\hline Acupressure group & $9.75 \pm 0.86$ & $5.55 \pm 0.61$ & -4.2 & -7.56 & 0.0001 \\
\hline $\begin{array}{l}\text { Acupressure + Lemon } \\
\text { group }\end{array}$ & $9.30 \pm 0.65$ & $4.45 \pm 0.25$ & -4.85 & -8.83 & 0.0001 \\
\hline Control group & $7.20 \pm 0.62$ & $7.40 \pm 0.53$ & 0.2 & 1.00 & 0.33 \\
\hline \multicolumn{6}{|l|}{ Nausea } \\
\hline Acupressure group & $5.30 \pm 0.37$ & $3.75 \pm 0.40$ & -1.55 & -10.1 & 0.0001 \\
\hline $\begin{array}{l}\text { Acupressure + Lemon } \\
\text { group }\end{array}$ & $6.15 \pm 0.29$ & $1.85 \pm 0.18$ & -4.3 & -12.33 & 0.0001 \\
\hline $\begin{array}{l}\text { Control group } \\
\text { Koping }\end{array}$ & $4.40 \pm 0.37$ & $4.55 \pm 0.38$ & 0.15 & 1.37 & 0.186 \\
\hline Acupressure group & $21.45 \pm 0.78$ & $24.65 \pm 0.62$ & 3.2 & 5.9 & 0.0001 \\
\hline $\begin{array}{l}\text { Acupressure + Lemon } \\
\text { group }\end{array}$ & $19.30 \pm 0.94$ & $25.50 \pm 0.55$ & 6.2 & 8.4 & 0.0001 \\
\hline Control group & $20.85 \pm 1.16$ & $21.35 \pm 0.92$ & 0.5 & 0.42 & 0.67 \\
\hline
\end{tabular}

Variable family support also enhances the coping abilities of pregnant women (Table 4); however, the increase is not significant. The value of R2 obtained is 0.29 which means that treatment and support groups contribute to improving the coping ability of pregnant women by $29 \%$. On the maternal coping ability variable pregnant, the acupressure treatment group and acupressure + lemon improve the significant coping ability of pregnant women. The biggest increase in coping value is in the acupressure + lemon aromatherapy group after being controlled by variables family support (Tables 5 and 6 ).

Table 4: ANOVA analysis table treatment group for nausea, vomiting, and coping

\begin{tabular}{llll}
\hline Variable & Mean \pm SD & $\mathrm{F}$ & $\mathrm{p}$ value \\
\hline Nausea & & & 0.001 \\
$\quad$ Acupressure group & $-4.2 \pm 2.48$ & 34.8 & \\
$\quad$ Acupressure + Lemon group & $-4.85 \pm 2.45$ & & \\
$\quad$ Control group & $0.20 \pm 0.89$ & & 0.0001 \\
Throw up & & & \\
$\quad$ Acupressure group & $-1.55 \pm 0.68$ & 96.3 & \\
$\quad$ Acupressure + Lemon group & $-4.30 \pm 1.56$ & & \\
$\quad$ Control group & $0.15 \pm 0.49$ & & \\
\hline
\end{tabular}

\section{Discussion}

Non-pharmacological therapy is a type of complementary nursing therapy that can be used as an intervention to overcome nausea and vomiting acupressure and aromatherapy [11], [12]. An alternative to deal with nausea, vomiting in nonpharmacological pregnancy is to use an aqua pressure aromatherapy [13]. Aromatherapy, which is a branch of herbal science, is the collection of methods for skillful, and controlled use of essential oils to promote the physical, emotional, and psychological health [14], [15]. Aromatherapy can be used by pregnant women for reducing nausea, vomiting, and coping. The results of statistical analysis show decline nausea in the group given acupressure and acupressure + aromatherapy by 4.2 and 4.85 . The reduction in nausea in the lemon acupressure + aromatherapy group was higher when compared to the acupressure group. In similar studies also found that patients in the treatment group, who used the acupressure ring between days 4 and 6 , experienced a decrease in nausea and vomiting compared to pre-treatment days 1-3 [16].

Table 5: Correlation between age and family support for nausea, vomiting, and coping abilities

\begin{tabular}{|c|c|c|c|c|c|c|}
\hline \multirow[t]{2}{*}{ Variable } & \multicolumn{2}{|c|}{ Nausea } & \multicolumn{2}{|c|}{ Throw up } & \multicolumn{2}{|c|}{ Koping } \\
\hline & Coef. & $p$ value & Coef. & $p$ value & Coef. & $p$ value \\
\hline Age & -0.09 & 0.49 & 0.07 & 0.60 & 0.06 & 0.61 \\
\hline Family support & -0.41 & 0.001 & -0.58 & 0.001 & 0.45 & 0.003 \\
\hline
\end{tabular}

Acupressure therapy and acupressure + lemon are effective in reducing nausea experienced by the mother pregnant. Paired t-test results in acupressure therapy and acupressure + lemon aromatherapy in mothers pregnancy can reduce vomiting by 1.55 and 4.3 , whereas in the control group increase in nausea by 0.2 , and an increase in the duration of vomiting by 0.15 . The most effective acupressure + lemon aromatherapy group reduces vomiting in mothers pregnant when compared to the other two groups. Skin essential oil extract lemons contain limonene, myrcene, linalool, octanal, dean, citronellal, neral, geranial, valensen, $\beta$ synonymous, and financial $\alpha$ are useful for suppressing nausea and preventing the occurrence of vomiting.

Table 6: Analysis coefficient values in groups and support for the ANOVA test for nausea, vomiting, and coping

\begin{tabular}{lllll}
\hline Variable & Coef. & $\mathrm{t}$ & $\mathrm{p}$ value & $\mathrm{R}^{2}$ \\
\hline Nausea & & & & \\
$\quad$ Acupressure group & -4.42 & -6.4 & 0.0001 & \\
$\quad$ Acupressure + Lemon group & -5.11 & -5.6 & 0.0001 & 0.55 \\
$\quad$ Control group & Ref & - & - & \\
$\quad$ Support & 0.01 & 0.10 & 0.922 & \\
Throw up & & & & \\
$\quad$ Acupressure group & -1.76 & 5.24 & 0.0001 & 0.77 \\
$\quad$ Acupressure + Lemon group & -4.68 & 10.41 & 0.0001 & \\
$\quad$ Control group & Ref & - & - & \\
Support & 0.04 & 0.73 & 0.47 & \\
Koping & & & & 0.29 \\
Acupressure group & 2.33 & 1.86 & 0.07 & \\
$\quad$ Acupressure + Lemon group & 4.39 & 2.62 & 0.01 & \\
$\quad$ Control group & Ref & Ref & - & \\
$\quad$ Support & 0.24 & 1.14 & 0.26 & \\
\hline
\end{tabular}

Paired t-test results for coping abilities obtained results that acupressure therapy, acupressure + aromatherapy lemon, and experience control increase in the average value of coping skills. The biggest pregnancy lies in the treatment of acupressure + lemon aromatherapy for 6.2. The therapeutic treatment with acupressure also increased in 3.2. and the control group (0.50). Acupressure + group Greater lemon aromatherapy increases the coping abilities of pregnant women by 5.7 compared to the control group. Acupressure + aromatherapy group lemons differ significantly in improving maternal coping skills pregnant compared to the acupressure group. Effective group with improved Coping skills of pregnant women is group acupressure + lemon aromatherapy. The results of the study also showed that support families will reduce nausea and vomiting by 0.41 and 0.58 , respectively. Family support will increase the coping abilities of pregnant women by $(0.45)$. Family and relative support can help improve abilities coping and reducing stress 
in pregnant women [17]. Giving aromatherapy with orange, for 3 times in a $24 \mathrm{~h}$, is more effective and efficient to reduce the intensity of nausea and vomiting in a pregnant women. The provision of aromatherapy does not interfere with the activities of pregnant women. Influence lemon oil has a feeling of being relaxed because its main chemical content lavender oil is linalool which can increase circulation and delivering electron chemical messages to the central nervous system [18].

\section{Conclusion}

Acupressure therapy and acupressure + lemon are effective in decreasing nausea by pregnant women. Lemon acupressure + aromatherapy therapy reduces average nausea significantly in pregnant women. The paired results of nausea and vomiting in the group acupressure and acupressure + aromatherapy lemons decrease in the amount of nausea with a decrease of 4.2 and 4.85 , respectively. This decrease is very significant with $p=0.0001(p<0.05)$. The duration of vomiting also decreased by 1.55 and 4.3 with a $p=0.0001(p<0.05)$. ANOVA test results in the treatment group coping abilities show that the lemon acupressure + aromatherapy group is more large increases the coping ability of pregnant women by 5.7 compared to the control group. Treatment groups and family support contribute to a reduction in nausea in pregnant women by $55 \%$, reduction in vomiting by $77 \%$, and ability coping of pregnant women by $29 \%$. Results of paired testing of coping abilities in pregnant women with acupressure therapy were 3.2 and acupressure + lemon aromatherapy treatment was equal to 6.2. The increase in both treatments was significant with a $p=0.0001$, respectively.

\section{References}

1. Lacasse A, Rey E, Ferreira E, Morin C, Bérard A Nausea and vomiting of pregnancy: What about quality of life? BJOG. 2008;115(12):1484-93. https://doi. org/10.1111/j.1471-0528.2008.01891.x

PMid:18752585

2. Wood H, McKellar LV, Lightbody M. Nausea and vomiting in pregnancy: Blooming or bloomin' awful? A review of the literature. Women Birth. 2013;26(2):100-4. https://doi. org/10.1016/j.wombi.2012.10.001

PMid:23200815

3. Pasha H, Behmanesh F, Mohsenzadeh F, Hajahmadi M, Moghadamnia AA. Study of the effect of mint oil on nausea and vomiting during pregnancy. Iran Red Crescent Med J. 2012;(11):727-30. https://doi.org/10.5812/ircmj.3477 PMid:23396673.

4. Matthews A, Dowswell T, Haas DM, Doyle M, O'Mathúna DP Interventions for nausea and vomiting in early pregnancy.
Cochrane Database Syst Rev. 2010;8(9):CD007575

PMid:14583914

5. Igarashi T. Physical and psychologic effects of aromatherapy inhalation on pregnant women: A randomized controlled trial. J Altern Complement Med. 2013;19(10):805-10. https://doi. org/10.1089/acm.2012.0103 PMid:23410527.

6. Hines S, Steels E, Chang A, Gibbons K. Aromatherapy for treatment of postoperative nausea and vomiting. Cochrane Database Syst Rev. 2018;10(3):CD007598. https://doi.org/10.1002/14651858. PMid:29523018.

7. Ali B, Wabel N, Shams S, Ahamad A, Khan SA, Anwar F. Essential oils used in aromatherapy: A systemic review. Asian Pac J Trop Biomed. 2015;5(8):601-11.

PMid:23410527

8. Lakhan SE, Sheafer H, Tepper D. The effectiveness of aromatherapy in reducing pain: A systematic review and metaanalysis. Pain Res Treatment. 2016;13:8158693. http://dx.doi. org/10.1155/2016/8158693

9. Javad C, Valadi S. Effects of anti-nociceptive and antiinflammatory component of limonene in herbal drugs. Iran J Med Aromatic Plants. 2010;26(3):415-22

10. Kia PY, Safajou F, Shahnazi M, Nazemiyeh $H$. The effect of lemon inhalation aromatherapy on nausea and vomiting of pregnancy: A double-blinded, randomized, controlled clinical trial. Iran Red Crescent Med J. 2014;16(3):e14360. https:// dx.doi.org/10.5812\%2Fircmj. 14360 PMid:24829772.

11. Heazell A, Thorneycroft J, Walton V, Etherington I. Acupressure for the in-patient treatment of nausea and vomiting in early pregnancy: A randomized control trial. Am J Obstet Gynecol. 2006;194(3):815-20. https://doi.org/10.1016/j.ajog.2005.08.042 PMid:16522418

12. Joulaeerad N, Ozgoli G, Hajimehdipoor H, Ghasemi E, Salehimoghaddam F. Effect of aromatherapy with peppermint oil on the severity of nausea and vomiting in pregnancy: A singleblind, randomized, placebo-controlled trial. J Reprod Infertil. 2018;19(1):32-8

PMid:29850445

13. Nasiri A, Mahmodi MA. Aromatherapy massage with lavender essential oil and the prevention of disability in ADL in patients with osteoarthritis of the knee: A randomized controlled clinical trial. Complement Ther Clin Pract. 2018;30:116-21. https://doi. org/10.1016/j.ctcp.2017.12.012

PMid:29389470

14. Namazi M, Akbari SA, Mojab F, Talebi A, Majd HA, Jannesari S. Effects of Citrus aurantium (bitter orange) on the severity of firststage labor pain. Iran J Pharm Res. 2014;13(3):1011-8. PMid:25276203.

15. Karaman S, Karaman T, Tapar H, Dogru S, Suren M. A randomized placebo-controlled study of aromatherapy for the treatment of postoperative nausea and vomiting. Complement Ther Med. 2019;42:417-21. https://doi.org/10.1016/j.ctim.2018.12.019 PMid:30670276

16. Gürkan OC, Arslan H. Effect of acupressure on nausea and vomiting during pregnancy. Complement Ther Clin Pract. 2008;14(1):46-52. https://doi.org/10.1016/j.ctcp.2007.07.002 PMid:18243942

17. Faramarzi M, Amiri FN, Rezaee R. Relationship of coping ways and anxiety with pregnancy specificstress. Pak J Med Sci. 2016;32(6):1364-9. https://dx.doi. org/10.12669\%2Fpjms.326.10892

PMid: 28083027

18. Indah SY. Keajaiban Kulit Buah. Surabaya: Tibbun Media; 2013. 